but levels of up to $6 \mathrm{mg} \%$ have been recorded (Lous, 1954).

Undoubtedly, acute barbiturate toxicity is associated with the development of neurological signs, such as depressed tendon reflexes and extensor plantar responses (Carroll, 1969) but it is of interest that both patients showed these changes without gross respiratory or cardiovascular depression.

Following recovery from coma, both patients admitted taking an overdose of drugs and both were found to be psychiatrically disturbed, much to the surprise and chagrin of their parents who, at the time of admission, had unwittingly misled the attendant medical staff.

Acute barbiturate poisoning should therefore be considered in any epileptic patient presenting with atypical coma, even when there is no evidence of possible overdose or of psychiatric instability.

\section{Acknowledgments}

I am grateful to Dr E. W. J. Gumpert for his encouragement and to Dr Gumpert and Dr J. Carson for allowing me to report details of their patients.

\section{References}

Carroll, B.J. (1969) Barbiturate overdosage-presentation $\overline{\bar{O}}$ with focal neurological signs. Medical Journal of Australia, $\vec{\nabla}$ $1,1133$.

Elliotr, F.A. (1964) Clinical Neurology. 1st Edition, p. 64. ปู Philadelphia: Saunders.

GraHAM, J.D.P. (1962) The Diagnosis and Treatment of $\vec{\circ}$ Acute Poisoning, pp. 107, 137. London: Oxford Uni- $\vec{\exists}$ versity Press.

KESSEL, N. (1965) Self poisoning. British Medical Journal, 2, 1265.

Lous, P. (1954) Blood serum and cerebrospinal fluid levels and renal clearance of phenobarbitone in treated epileptics. Acta Pharmacologica et Toxicologica, 10, 166.

Scotr, D.F. (1968) Psychiatric aspects of epilepsy. Postgraduate Medical Journal, 44, 319.

\title{
Ergotamine-induced venous thrombosis
}

U. MiNTZ
M.D.
S. BAR-MEIR

M.D.

\section{Summary}

A patient is described who developed venous thrombosis in the leg following an intramuscular injection of ergotamine tartrate.

\section{Introduction}

Ergotamine poisoning in the human classically manifests as arterial spasm and arterial thrombosis, sometimes leading to gangrene of the extremities. We wish to report a rare vascular complication of ergotamine treatment, venous leg thrombosis which appeared in a woman following an intragluteal injection of ergotamine tartrate given for menorrhagia.

\section{Case report}

The patient, a female teacher, aged 38 years, mother of two healthy children, was admitted with the complaint of pain in her left calf. Four days earlier she had severe migraine and took $5 \mathrm{~g}$ of aspirin instead of the ergotamine tartrate tablets she was wont to use but which were out of stock. The next morning, on the expected day, her menstruation started, this time, however, with excessive blood loss to an extent she had never experienced before. The $\frac{7}{2}$ severe menorrhagia continued for 3 days until at 10.30 a.m. on the day of admission she received an $N$ intragluteal injection of $0.5 \mathrm{mg}$ ergotamine tartrate. Three quarters of an hour later she felt a cramp in the neck muscles and a sensation of severe burning $\omega$ pain radiating along both thighs downward. On lying down the burning pain disappeared but when $\stackrel{\circ}{\circ}$ she tried to rise at 13.00 p.m. she felt a sharp pain $ळ$ in the left calf preventing her from standing. Since $?$ the pain continued unabated she was admitted at ${ }_{0}$ 18.30 p.m. Noteworthy in her history are frequent $\frac{\vec{D}}{\mathrm{D}}$ attacks of severe migraine of many years duration for which she had been taking various analgesics, $\stackrel{\AA}{\varrho}$ 
among them acetylsalicylic acid in doses up to $2 \mathrm{~g} /$ day and ergotamine tartrate in doses up to $7 \mathrm{mg} /$ day, always orally.

On examination she was afebrile with a normal pulse and blood pressure. The only abnormal finding was a moderate swelling of the left leg extending from below the knee to the ankle with extreme tenderness of the left calf and a positive Homans' sign; $15 \mathrm{~cm}$ below the knee the contour of the left leg was $1.5 \mathrm{~cm}$ larger than that of the right leg. There was no oedema, nor did the leg show a change in temperature or colour. The peripheral arterial pulses were normally palpable. Venous thrombosis in the left leg was diagnosed. Routine laboratory examinations, including bleeding time, platelet count, clotting time, clot retraction, plasma fibrinogen, one-stage plasma prothrombin and partial thromboplastin time, all were normal. She was treated with phenylbutazone and the pain, the swelling and the Homans' sign receded within 9 days. She was discharged on the eleventh day with a normal contour of the left calf, and warned to abstain from aspirin and ergotamine. Oscillometric examination of both legs performed 1 month later was normal. Follow-up for a period of 4 months thus far showed patient to have normal menstruation.

\section{Discussion}

The sequence of events in this patient reflects a double iatrogenic reaction, acetylsalicylic acidinduced menorrhagia followed by ergotamineinduced venous thrombosis. Menorrhagia due to aspirin is a known adverse reaction to this drug (Meyler and Herxheimer, 1972) and the presumption of a similar etiology for the menorrhagia in our patient agrees with her negative previous history for menorrhagia, the large doses of aspirin she had taken prior to the bleeding, and the normal menstruation she has now while abstaining from aspirin.

The assumption of the causation of the venous thrombosis by the ergotamine injection rests on the time sequence, on the history of muscle spasm and of burning pain radiating along the lower extremities (Greene, 1959), possibly reflecting sudden ischemia, preceding the pain and swelling in the calf.

Ergotamine is an ergot alkaloid derived from the so-called ergot fungi, specifically the claviceps species. The two general types of ergot toxicity are the gangrenous and the convulsive which appeared as epidemics in the middle ages, when the burning sensation in the extremities and the necrosis were called 'St Anthony's fire' or 'holy fire' (Cameron and French, 1960). The toxicity of ergotamine, a lysergic acid derivative, manifests mainly in its action on the smooth muscles of the arteries and arterioles, resulting in spasm, damage to the endo- thelium and arterial thrombi (Yater and Cahill, 1936). The spasm may involve various arteries, mostly those of the extremities, but also the aorta the renal and the mesenteric arteries (Hessov, Kroman-Andersen and Madsen, 1972). Although in most cases of ergotamine intoxication the drug had been taken for prolonged periods of time and/or in high dose, specific sensitivity has been postulated in some patients.

Regarding the ergotamine intoxication in our patient the following may be pertinent. Firstly, the drug, when liver function is normal, is rapidly metabolized so that it does not accumulate in the body; however, when intoxication occurs after prolonged use endothelial damage might play a role (Yater and Cahill, 1936). Secondly, the absorption of the drug is rather poor; a parenterally administered dose may be 8-10 times as effective as an equal amount orally (Davis, Adir and Pearl, 1936). Thirdly, cases of ergotamine poisoning are known, even ending in death, having occurred following the parenteral administration of small amounts, even $0.5 \mathrm{mg}$ (Goodman and Gilman, 1970). Noteworthy is the case of a woman who took ergot preparations for years orally without symptoms of intoxication, but who developed arterial spasm when she changed to parenteral treatment (Fairbairn, 1958). A similar course of events could have taken place in our patient.

Thrombophlebitis in the human following administration of an ergot preparation was mentioned only once in the literature at our disposal (Greene, 1959). On the other hand, in addition to arterial spasm, venous spasm is known to occur as a reaction to ergotamine (Cranley et al., 1970), and in experiments with ergotoxine in fowl venous thrombosis developed in the comb in addition to arterial thrombosis (Lewis, 1935). Furthermore, according to Juergens and Payne (1972) in the human venous thrombosis may develop in the deep veins of the extremities as result of severe ischemia due to sudden arterial occlusion with ensuing slowing of blood flow and venous endothelial damage.

\section{References}

Cameron, E.N. \& French, E.B. (1960) St Anthony's fire rekindled: Gangrene due to therapeutic dose of ergotamine. British Medical Journal, 2, 28.

Cranley, J.J., Raymond, J.K., Strasser, E.S. \& Charles, D.H. (1963) Impending gangrene of four extremities secondary to ergotism. New England Journal of Medicine, 269, 727.

Davis, M.E., Adir, F.L. \& Pearl, S. (1936) The present status of oxytocics in obstetrics. Journal of American Medical Association, 107, 261.

FAIRBAIRN, J.F. (1958) Severe arteriospastic disease secondary to use of ergot preparations. Medical Clinics of North America, 42, 971.

Greene, R. (1959) Migraine. British Medical Journal, 1, 574. 
Goodman, L.S. \& Gilman, A. (1970) The Pharmacological Basis of Therapeutics. Fourth Edition. The Macmillan Co., London, p. 902.

Hessov, I., Kraman-Andersen, C. \& Madsen, B. (1972) Peripheral arterial insufficiency during ergotamine treatment. Danish Medical Bulletin, 19, 236.

Juergens, J.L. \& PAYNe, W.S. (1972) Obstructive diseases of veins. In: Peripheral Vascular Diseases (Ed. by J. F. Fairbairn, J. L. Juergens and J. A. Spittel). Saunders Co., p. 558.
LEWIS, T. (1935) The manner in which necrosis arises in the fowl's comb under ergot poisoning. Clinical Science, 2, 43.

Meyler, L. \& Herxheimer, A. (1972) Side effects of drugs. Excerpta Medica, Vol. 7, 138.

YATER, W.M. \& CAHILL, J.A. (1936) Bilateral gangrene of feet due to ergotamine tartrate used for pruritus of jaundice, report of a case studied arteriographically and pathologically. Journal of American Medical Association, 106, 1625.

\title{
Malignant mucocele of the appendix in a femoral hernia
}

\author{
I. N. NAYAK* \\ M.S., F.R.C.S. \\ Hillingdon Hospital, Uxbridge, Middlesex
}

\begin{abstract}
Summary
A case of malignant mucocele of the appendix caused by constriction of its base at the neck of a femoral hernial sac is described. No similar case has been found after a careful search of the literature.
\end{abstract}

\section{Case report}

History. A 62-year-old female patient was admitted for an elective operation for a femoral hernia. She had noticed a swelling in the right groin which had gradually increased in size over the previous 5 years. The swelling had never been reducible during this period and had caused her little discomfort. Twelve years previously she had undergone a hysterectomy for large uterine fibroids and she had suffered from recurrent attacks of bronchitis for many years.

Examination. The patient was moderately obese and had an irreducible giant right femoral hernia approximately $15 \times 10 \times 7 \mathrm{~cm}$ in size (Fig. 1). This was not tender and a cough impulse was present.

Operation. The hernia was explored through an oblique inguinal incision. The sac contained omentum, transverse colon and the appendix which was constricted at its base by the neck of the sac, and was distended and cystic (Fig. 2). The caecum was normal and there was no evidence of pseudomyxoma peritonei. After reducing the omentum and the transverse colon into the general peritoneal cavity an appendicectomy was performed, care being taken

\footnotetext{
* Present address: Children's Hospital, Medical Center, Boston, U.S.A.
}

not to spill its contents. The peritoneum was closed and the femoral ring repaired by suturing the inguinal ligament to the pectineal ligament. Post operatively she made an uninterrupted recovery.

Pathology. The appendix measured $9 \times 2.5 \times 2.5$ $\mathrm{cm}$, and was filled with mucus distal to a constriction at its base (Fig. 3). Histology showed papillary hyperplasia of the epithelium and invasion of the submucosa and muscle coat (Fig. 4). These features are those of a malignant mucocele of the appendix.

\section{Discussion}

Incidence. The term 'mucocele of the appendix' was first coined by Fere in 1877 though the condition had earlier been recognized by Rokitansky in 1842 and described by Virchow in 1863 (Andrews, Feller and Crenwelge, 1966). Since then over 600 cases have been reported in the literature (Chan King-Pan, 1965). The incidence varies from $0 \cdot 1-0.3 \%$ of surgically removed specimens, and from 0.003 $1.3 \%$ of surgically removed specimens, and from $0.003-1.5 \%$ of autopsy specimens (Andrews et al., 1966). DeGarengeot in 1731 was the first to describe the appendix as the content of a hernial sac and an operation for appendicitis in a femoral hernia was described by Hevin in 1785 (Watson, 1948). Appendix as the sole content of a femoral hernia was probably first reported by Langton in 1891 (Chatterjee, 1966). Appendicocele along with other viscera occurs in $1-1.5 \%$ of all hernias but a pure appendicular hernia is rare, $0.003 \%$ (Watson, 1948). About 240 cases of appendix alone in a femoral hernia have 